\title{
USO POPULAR DE RECURSOS VEGETAIS E PERFIL SOCIOECONÔMICO de moradores de comunidades rurais de Sinop, Mato Grosso, BRASIL
}

\author{
Maira Luiza Spanholi ${ }^{1 *}$, Marliton Rocha Barreto ${ }^{1}$
}

${ }^{1}$ Universidade Federal de Mato Grosso, Programa de Pós-Graduação em Ciências Ambientais - PPGCAM / ICNHS, Câmpus Universitário de Sinop. Av. Alexandre Ferronato, 1200, CEP: 78557-267, Sinop, MT, Brasil.

*Autorpara correspondência:maira_luiza15@hotmail.com

Recebido em 05 de julho de 2017. Aceito em 05 de março de 2018. Publicado em 14 de abril de 2018.

REsumo - As plantas são essenciais à sobrevivência humana, sendo utilizadas para suprir diversas demandas e resgatar o conhecimento tradicional sobre a utilização delas possibilita a transmissão de informações entre gerações. O objetivo da pesquisa foi apresentar o perfil socioeconômico dos moradores de comunidades rurais no município de Sinop, Mato Grosso, descrevendo o uso popular dos recursos vegetais coletados e cultivados, estabelecendo a relação sociocultural e econômica entre as famílias botânicas e entrevistados. A metodologia utilizou técnica de lista livre e questionário semiestruturado, utilizando o processo de seleção Bola de Neve. A análise de regressão linear simples foi usada para verificar se a renda explica o número de plantas citadas. As comunidades estudadas foram: Brígida, 11 de Julho, Adalgisa, Agrovila, Planalto, Bom Jardim e Monalisa, com 226 pessoas entrevistadas. Foram citadas 2.885 plantas, sendo 217 espécies em 70 famílias botânicas. Pessoas de origem da região Sul do país e aquelas com idade superior a 50 anos conhecem maior quantidade de plantas. A análise de regressão revelou que a renda pode explicar a quantidade de plantas citadas pelos entrevistados. Uso das plantas como fontes de recursos alimentícios e medicinais garantem a subsistência dos entrevistados, porém a transmissão de conhecimentos entre as gerações está sendo perdida.

Palavras-chave: Etnobotânica; Etnoconhecimento; Saber Popular; Amazônia Meridional.

Popular use of Plant Resources and socioeconomic profile of RESidents of Rural Communities in Sinop, Mato Grosso, BrazIL

Abstract - Plants are essential to human survival, being used to meet diverse demands. Recovering traditional knowledge on their use enables the transmission of information between generations. The objective of this study was to present the socioeconomic profile of residents of rural communities in the municipality of Sinop, Mato Grosso, to describe the popular use of collected and cultivated plant resources which established a sociocultural and economic relationship between the botanical families and interviewed people. The methodology included the free list technique and semi structured questionnaire, using the Snowball selection process. The simple linear regression analysis was used to verify if the income explains the number of cited plants. The communities included in the study were: Brígida, 11 de Julho, Adalgisa, Agrovila, Planalto, Bom Jardim and Monalisa, with 226 people interviewed. There were 2,885 plants cited, 217 species in 70 botanical families. People from the southern region of the country and those over the age of 50 know more plants. The regression analysis revealed that income could explain the number of plants cited by the interviewees. Use of plants as food and medicinal sources guarantee the subsistence of the interviewees, but the transmission of knowledge between the generations is being lost.

Keywords: Ethnobotany; Ethno knowledge; Popular KNowledge; Southern Amazonla. 


\section{USO POPULAR DE LOS RECURSOS VEGETALES Y PERFIL SOCIOECONÓMICO DE LOS HABITANTES DE LAS COMUNIDADES RURALES DE Sinop, Mato Grosso, Brasil}

REsumen - Las plantas son esenciales para la supervivencia humana, siendo utilizadas para suplir diversas demandas y rescatar el conocimiento tradicional sobre su utilización, lo que posibilita la transmisión de informaciones entre generaciones. El objetivo de la investigación fue presentar el perfil socioeconómico de los habitantes de las comunidades rurales en el municipio de Sinop, Mato Grosso, describiendo el uso popular de los recursos vegetales recolectados y cultivados, estableciendo la relación sociocultural y económica entre las familias botánicas y entrevistados. La metodología utilizó técnica de lista libre y cuestionario semiestructurado, utilizando el proceso de selección Bola de Nieve. Y análisis de regresión lineal simple para verificar si la renta explica el número de plantas citadas. Las comunidades estudiadas fueron: Brígida, 11 de Julio de Adalgisa, Agrovila, Planalto, Bom Jardim y Monalisa, con 226 personas entrevistadas. Fueron citadas 2.885 plantas, con 217 especies en 70 familias botánicas. Las personas de origen del sur del país y los mayores de 50 años conocen mayor cantidad de plantas. El análisis de regresión reveló que la renta puede explicar la cantidad de plantas citadas por los encuestados. El uso de las plantas como fuentes de recursos alimenticios y medicinales garantiza la subsistencia de los entrevistados, pero la transmisión de conocimientos entre las generaciones está siendo perdida.

Palabras clave: Etnobotánica; Etnoconocimiento; Saber Popular; Amazonla Meridional.

\section{INTRODUÇÃO}

Em todo o território brasileiro existem comunidades tradicionais e de pequenos agricultores que cultivam em pequena escala uma ampla diversidade de espécies e de variedades vegetais em áreas nativas. Esse cultivo é importante para essas comunidades, pois os produtos são oferecidos no pequeno comércio auxiliando na renda familiar e parte do que é produzido serve para a subsistência. Portanto, manter a diversidade de plantas é importante para essas comunidades, pois além do uso de plantas cultivadas, também são utilizados recursos naturais circundantes a estas comunidades (Pilla e Amorozo 2009).

Muitas comunidades rurais mantem forte ligação e dependência dos recursos vegetais locais, mesmo com o desenvolvimento tecnológico atual e o cultivo de algumas espécies complementam a demanda alimentar e necessidades básicas de sobrevivência das famílias, consequentemente essas áreas produtivas minimizam a pobreza (Lucas et al. 2015). As plantas são utilizadas de diversas maneiras, como: alimentação, vestimenta, cura de doenças, abrigo, entre outras (Balick e Cox 1997).

A comunidade em que uma pessoa está inserida influencia no uso dos recursos vegetais, além disso, essa utilização também depende do conhecimento obtido, geralmente, com seus antepassados. Comunidades rurais detém grande conhecimento sobre plantas, tanto nativas quanto exóticas, porque essas suprem diversas necessidades, especialmente, alimentícias e medicinais, com a utilização das plantas para chás, xaropes, entre outras formas de uso. A utilização desses recursos vegetais não é somente determinada por características físicas e biológicas de determinado habitat, mas também pelo conhecimento individual e coletivo, por decisões familiares, sociais, econômicas e condições políticas (Schutkowski 2006).

O estudo das formas de uso das plantas é importante para entender a dinâmica de quem vive em comunidades distantes de centros urbanos, o estudo dessa interação é feito pela etnobotânica, que é entendida como o estudo das interações entre homens e plantas, tendo por objetivo a percepção e classificação do nome, formas de uso e manejo das espécies vegetais por parte de comunidades locais (Strachulski e Floriani 2013). Portanto o resgate da cultura e do conhecimento das populações tradicionais é fundamental para entender a dinâmica de uso das 
plantas (Diegues 2000).

A diversidade biológica do Estado de Mato Grosso está intimamente relacionada com a própria extensão territorial, privilegiada com a complexidade de biomas e rica diversidade étnica e cultural, os quais favorecem estudos na área (Albuquerque 2007). O bioma amazônico vem sofrendo interferência humana inadequada desde a década de 1990, exigindo da sociedade uma perspectiva de aproveitamento socioeconômico mais elaborada e consistente no aspecto do conhecimento da sua vegetação (Veiga 2011). Portanto, os estudos etnobotânicos são fundamentais para resgatar o conhecimento sobre as plantas dos habitantes dessa região.

No Estado de Mato Grosso os conhecimentos e informações contidas em todas as comunidades (indígenas, ribeirinhas, quilombolas, pantaneiras, etc.) e no próprio meio urbano são transferidos entre proles contribuindo para a riqueza cultural, econômica, social e biológica. Uma investigação pertinente na área da etnobotânica e que evidencia a importância do conhecimento humano está inserida em trabalhos realizados em quintais, seja em áreas rurais quanto em áreas urbanas. Os estudos embasados em quintais são significativos por apresentarem aspectos cotidianos e de conhecimento comum ou não entre familiares o que possibilita uma ponte entre saber tradicional e as pesquisas de cunho científico (Oliveira 2013).

Os quintais são utilizados há milênios como locais para cultivo de plantas e criação de animais, sendo compreendido como espaço de múltiplo uso próximo a residência. Sua composição e fisionomia são diversificadas, pois recebem diversas influencias como clima e vegetação natural da região, história de ocupação, contato com outras sociedades, entre outros (Amorozo 2008). Os quintais são arranjos complexos que traduzem o manejo local, pois se caracteriza por atividades experimentais simples, refletindo a forma como a população local vive. Além disso, através dessas atividades, necessidades básicas alimentícias e medicinais são supridas (Amorozo 2002b).

Os quintais promovem benefícios nutricionais, econômicos, ecológicos e de conservação de espécies, por serem sistemas agroflorestais são capazes de integrar várias atividades que melhoram a qualidade de vida da família. Com isso, muitas comunidades utilizam esse sistema agroflorestal de produção como meio de subsistência, além de proporcionar a transferência do grande conhecimento sobre uso e manejo da biodiversidade para as próximas gerações (Fracaro e Guarim 2008).

Desta forma, o presente artigo tem como objetivo apresentar o perfil socioeconômico dos moradores de comunidades rurais no município de Sinop, Mato Grosso, descrevendo o uso popular dos recursos vegetais coletados e cultivados, estabelecendo a relação sociocultural e econômica entre as famílias botânicas e os entrevistados.

\section{Material e mÉtodos}

Área de estudo

As comunidades estudadas estão localizadas na zona rural do município de Sinop, no médio Norte do Estado de Mato Grosso, no Centro Oeste do Brasil, compreendendo o bioma Amazônia. A região tem um clima do tipo tropical quente e úmido que é predominante do Centro-Norte do Estado, caracterizado pela presença de duas estações bem definidas: uma chuvosa, no período de outubro a abril e outra seca de maio a setembro, e pela pequena amplitude térmica anual, e por temperaturas e umidades elevadas: com médias anuais oscilando 
entre $24^{\circ} \mathrm{C}$ e $27^{\circ} \mathrm{C}$ (Dias 2007). A precipitação média anual é de $2000 \mathrm{~mm}$, sendo acima de $50 \%$ entre os meses dezembro e fevereiro e cerca de 1\% ocorrem historicamente, entre junho e agosto (Souza et al. 2013).

O estudo foi realizado entre janeiro e junho/2016 em comunidades que estão localizadas na zona rural de Sinop, Estado de Mato Grosso, na região Centro Oeste do Brasil (Tabela 1). As comunidades foram escolhidas com visita previa para verificação se os moradores estariam em casa durante o período diurno, pois como são próximas do centro urbano, muitos trabalham fora.

Tabela 1 - Coordenadas das comunidades estudadas no município de Sinop.

\begin{tabular}{|c|c|}
\hline Comunidade & Coordenadas \\
\hline Brígida & $11^{\circ} 49^{\prime} 44.3^{\prime \prime S} 55^{\circ} 26^{\prime} 13.0^{\prime \prime} \mathrm{W}$ \\
\hline 11 de Julho & $11^{\circ} 47^{\prime} 52.7^{\prime \prime S} 55^{\circ} 27^{\prime} 03.7^{\prime \prime} \mathrm{W}$ \\
\hline Adalgisa & $11^{\circ} 51^{\prime} 44.2^{\prime \prime S} 55^{\circ} 27^{\prime} 39.1^{\prime \prime} \mathrm{W}$ \\
\hline Planalto & $11^{\circ} 45^{\prime} 58.5^{\prime \prime S} 55^{\circ} 28^{\prime} 11.3 ” \mathrm{~W}$ \\
\hline Gleba Mercedes 5 & $11^{\circ} 30^{\prime} 00.7^{\prime \prime S} 55^{\circ} 41^{\prime} 37.5^{\prime \prime} \mathrm{W}$ \\
\hline Bom Jardim & $11^{\circ} 53^{\prime} 43.4^{\prime \prime S} 55^{\circ} 28^{\prime} 14.7 ’ \mathrm{~W}$ \\
\hline Monalisa & $11^{\circ} 55^{\prime} 08.2^{\prime \prime} \mathrm{S} 55^{\circ} 29^{\prime} 05.8^{\prime \prime} \mathrm{W}$ \\
\hline
\end{tabular}

Coleta de dados

Todos os informantes foram devidamente esclarecidos das atividades e, posteriormente, aqueles que aceitaram participar das entrevistas assinaram o termo de consentimento livre e esclarecido, documento que expressa sua participação voluntária. O levantamento etnobotânico foi autorizado pelo Comitê de Ética em Pesquisa Envolvendo Seres Humanos da Universidade de Cuiabá - UNIC, com o seguinte número de parecer: 1.386.702.

Foi adotada a técnica chamada Bola de Neve (amostragem não-probabilística), onde os elementos são escolhidos de forma intencional, para a seleção da amostra. Essa técnica funciona a partir de um primeiro contato com a comunidade, onde um informante é selecionado, a partir daí este passa a indicar outros informantes, que no caso deste trabalho, na maior parte das vezes foram os vizinhos ou parentes que residiam na mesma comunidade (Albuquerque et al. 2010).

A coleta de dados foi realizada pela citação livre de espécies pelo informante, através da chamada técnica de lista livre (Bernard 2006; Albuquerque et al. 2010). Para tanto, foi usada a seguinte pergunta: "Faz uso das plantas presentes em seu quintal para alguma finalidade como: artesanato, remédio, comida ou outros?” A partir dessa lista, uma nova etapa foi realizada por meio de entrevista semiestruturada, utilizando questionário para buscar o máximo de informação possível relacionada a cada espécie como o nome comum, uso, finalidade, etc. Também foram coletados os dados socioeconômicos, como nível de escolaridade, idade, profissão, renda mensal e tempo de residência.

Análise dos dados

Os dados obtidos nas entrevistas foram armazenados em um banco de dados em Microsoft Excel (Office 2013), e as análises estatísticas foram realizadas em Excel 2013. As espécies levantadas foram relacionadas por 
seus nomes científicos e família botânica. A identificação das espécies ocorreu por meio de fotografia delas em capo e posterior comparação com literatura específica. A classificação seguiu o sistema APG III (Angiosperm Phylogeny Group) consultadas através dos sites The Plant List para plantas exóticas e Flora do Brasil para plantas nativas.

Foi usada análise de regressão linear simples para verificar se a renda explica o número de plantas citadas pelos entrevistados, sendo considerada como variável explicada $(\mathrm{Y})$ o número de citações, e a variável explicativa (X) a renda.

Os dados socioeconômicos foram organizados da seguinte forma: idade, gênero (mulher, homem), renda familiar (de 1 até 2 salários mínimo, maior que 2 até 3 salários mínimo, maior que 3 até 4 salários mínimo, maior que 4 até 5 salários mínimo e maior que 5 até 6 salários mínimo), e nível de escolaridade (analfabetos, para pessoas que nunca frequentaram a escola; sabe ler e escrever, para pessoas que não frequentaram a escola mas que sabem ler e escrever; ensino fundamental incompleto; ensino fundamental completo; ensino médio incompleto; ensino médio completo; ensino superior incompleto; ensino superior completo e ensino técnico).

Foram consideradas plantas cultivadas aquelas disponíveis nos quintais dos entrevistados, ou seja, as plantas que estão próximas a residência. As plantas coletadas são aquelas que estão em áreas de mata próxima a residência, mas que os entrevistados precisam se deslocar de seus quintais para conseguirem as mesmas. Plantas exóticas foram consideradas aquelas que foram introduzidas no país de alguma forma, ou seja, não pertencem a flora brasileira. Já para as nativas foram consideradas aquelas naturais do Brasil, para determinação da origem as espécies foram consultadas no site Flora brasiliensis. Portanto, as plantas cultivadas e coletadas podem ser classificadas tanto como nativas quanto exóticas.

\section{Resultados E Discussão}

\section{Perfil socioeconômico dos entrevistados}

Foram entrevistadas um total de 226 pessoas nas comunidades selecionadas (Tabela 2). Desse total, 161 (71\%) eram do gênero feminino e 65 (29\%) do gênero masculino. Além disso, 95\% dos entrevistados informaram possuir casa própria e apenas 5\% moram de aluguel.

Tabela 2 - Número de entrevistados, sobre os recursos vegetais utilizados, nas comunidades rurais no município de Sinop

\begin{tabular}{lc}
\hline Comunidade & Número de entrevistados \\
\hline Brígida & 13 \\
11 de Julho & 27 \\
Adalgisa & 24 \\
Agrovila (Gleba Mercedes 05) & 42 \\
Planalto & 45 \\
Bom Jardim & 49 \\
Monalisa & 26 \\
\hline Total & $\mathbf{2 2 6}$ \\
\hline
\end{tabular}


Com relação à escolaridade dos informantes, o que predomina são os que possuem ensino fundamental incompleto, com 50\% das respostas, seguida de ensino médio completo, ensino fundamental completo, ensino superior incompleto, ensino superior completo, analfabetos, ensino médio incompleto, ensino técnico e os que sabem ler e escrever.

No que diz respeito a idade dos entrevistados, as respostas obtidas foram as seguintes: as pessoas de 51 até 60 anos foram as mais representativas, com 23\% no total, seguido das pessoas que possuem de 41 a 50 anos $(18 \%)$, de 61 a $70 \operatorname{anos}(16 \%)$, de 21 a 30 anos (16\%), de 31 a 40 anos (13\%), de 71 a 80 anos (8\%), de 11 a 20 anos $(5 \%)$ e mais de 80 anos $(1 \%)$. Como pode ser visto, mais da metade das pessoas estão na faixa etária de 41 a 70 anos.

Outra pergunta realizada aos informantes foi sobre a profissão, com isso as respostas obtidas demonstraram que $35 \%$ deles são do lar. Ainda 17\% informaram serem aposentados, $12 \%$ produtor rural, 3\% estudantes, $3 \%$ professores, além de outras diversas profissões como leiteiro ( $2 \%)$, pedreiro $(2 \%)$, autônomo $(2 \%)$, verdureiro $(2 \%)$, entre outras em menores porcentagens.

O tempo de moradia de 59\% dos entrevistados nas respectivas comunidades é de mais de 10 anos. Eles possuem costumes trazidos da região na qual possuem suas origens. A entrevista revelou que a predominância é da região Sul do país, com 51\% dos informantes. Além do Sul, houveram informantes de todas as regiões do país, destacando a região Centro Oeste que compreendeu 27\% dos entrevistados. Outros 12\% são da região Sudeste, $8 \%$ da região Nordeste e $1 \%$ da região Norte.

Com relação a renda dos entrevistados, foi levantado que 54\% ganham de 1 até 2 salários mínimos, 20\% de 2 até 3 salários mínimos, 12\% ganham até 1 salário mínimo, 10\% de 3 até 4 salários mínimos e 4\% recebem 4 ou mais salários mínimos.

\section{Relação com os recursos vegetais}

Foram citadas um total de 2.885 plantas, dentre essas 2.833 são plantas cultivadas em seus quintais, sendo 214 espécies. Para as coletadas, ou seja, aquelas que não estão nos quintais e precisam ser buscadas em regiões de mata perto da residência, foram 52 citações de 13 espécies. Em alguns casos, os quintais dos entrevistados se estendiam até a região de mata, que geralmente fica ao fundo da residência, portanto nessas propriedades há uma transição dos quintais até as matas, onde é possível coletar plantas mais facilmente. Com isso, o total de famílias botânicas levantadas na pesquisa foi 70, classificadas principalmente para uso alimentício, seguida de uso medicinal e por últimos classificadas como outros usos, por exemplo, sombra, alimento para a criação, artesanato.

Do total das plantas citadas, $66 \%$ foram para alimentação, 31\% uso medicinal e 4\% outros usos, como sombra, artesanato, lenha e pesca (Figura 1). Segundo Hanazaki (2006), o conhecimento que as comunidades possuem sobre o meio ambiente podem interferir nas práticas cotidianas, e o conhecimento local acerca da vegetação, inclui também muitas plantas utilizadas com finalidades medicinais, alimentícias, para artesanatos, ornamentais, ou como alimento para fauna.

Numa dada população, nem todos os membros conhecem todas as plantas; no entanto, as mulheres, quase sempre envolvidas diretamente no tratamento de seus filhos e maridos, são, em geral, as principais depositárias do saber popular quanto ao uso das plantas (Pasa 2011). 
Do total de plantas citadas, $70 \%$ foram mencionadas pelas mulheres entrevistadas e 30\% pelos homens. O conhecimento difere entre homens e mulheres, e isso pode ser explicado através do papel que cada um exerce nas comunidades. Essa diferença de conhecimento geralmente acontece por uma questão cultural. As mulheres utilizam as plantas que geralmente estão em ambientes mais próximos a residência, onde entram em maior contato com roças e quintais, enquanto os homens conhecem mais espécies nativas devido ao seu envolvimento em atividades que proporcionam maior proximidade aos ambientes de florestas naturais da região (Lunelli 2014).

Figura 1 - Principais famílias botânicas citadas pelas comunidades rurais estudadas em Sinop e sua principal utilização. A: Alimentação; B: Medicinal; C: Outros usos.

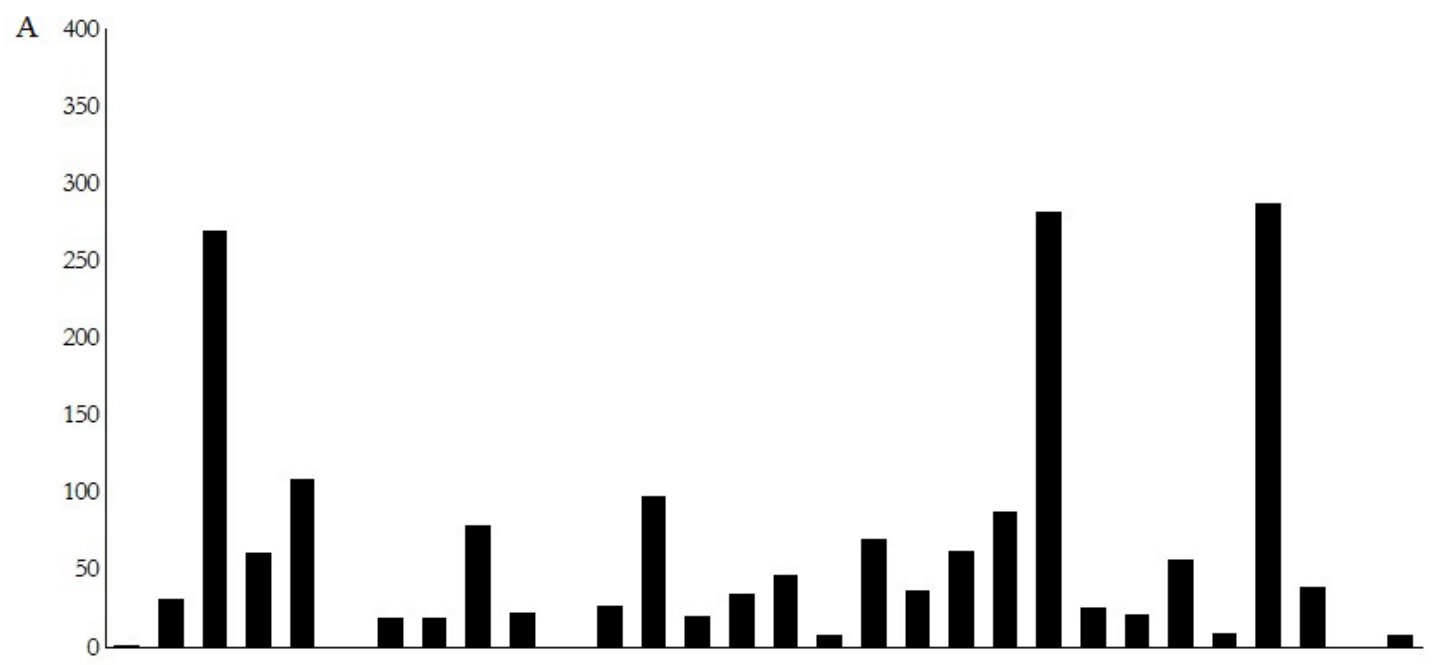

B
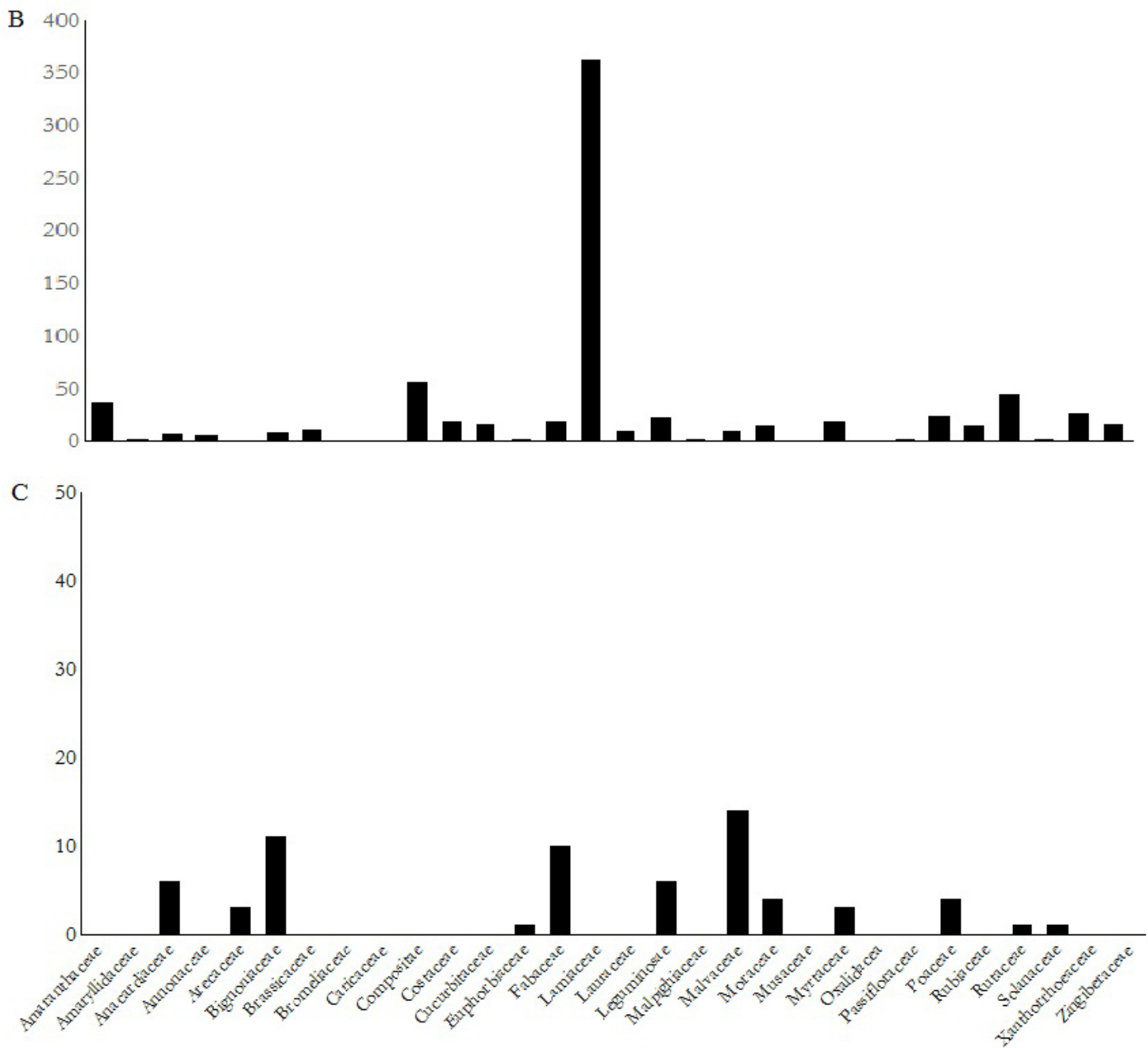
As diferenças no conhecimento de plantas entre mulheres e homens difere em grande parte por conta da questão cultural de cada indivíduo, onde as mulheres aprender a trabalhar com as plantas que a mãe ensina e os homens seguem os ensinamentos dos pais.

Segundo Poderoso (2012), as variações intraculturais no conhecimento relacionadas ao gênero são exemplificadas por estudos que mostram a diferença no conhecimento de homens e mulheres. As mulheres geralmente conhecem mais espécies medicinais e alimentícias, porque são essas plantas que mais usam em seu cotidiano. Já os homens tem maior afinidade com espécies arbóreas, pois servem para construção de casas, currais, entre outras. Isso ocorre pois homens e mulheres possuem papéis diferentes no acesso, uso e manejo dos ambientes naturais e cultivados (Martin 1995; Ruddle 2000; Hanazaki 2004).

Com relação a faixa etária, as pessoas de 51 até 60 anos foram as que citaram o maior número de espécies (836), considerando a frequência relativa, isso representa $29 \%$ das citações, sendo assim, foi a faixa etária com maior número de plantas citadas. Vários estudos indicam que diferenças intra e interculturais na percepção, como a idade, a função social do indivíduo e o tempo de moradia pode influenciar nossas percepções sobre a natureza (Albuquerque 2014). No geral, as pessoas até 50 anos citaram 1.276 plantas (44\%) e as de 51 anos acima citaram 1.609 plantas $(56 \%)$.

Quando se trata do grau de conhecimento sobre plantas por meio da idade é difícil comparar, pois as pessoas com mais idade tendem a possuir maior conhecimento sobre os recursos vegetais que as pessoas mais jovens, isso porque elas tiveram mais oportunidade de conhecer e utilizar a vegetação.

Os jovens preferem suprir suas necessidades com outros recursos que não sejam as plantas e muitas vezes não sentem vontade de buscar o conhecimento relacionado aos recursos vegetais que podem estar disponíveis para uso sem a necessidade de compra, devido ao seu estilo de vida moderno, com isso o interesse a respeito da busca por plantas é menor. Porém, um fator que afeta o conhecimento sobre plantas nas pessoas idosas, podendo reduzi-lo, são as perdas na memória. Em algumas entrevistas pode ser percebido que o informante sabia sobre um tipo de planta, mas não conseguia lembrar seu nome ou sua forma de preparo, por exemplo.

Uma das questões principais que pôde ser percebida, é que a preocupação maior não é com o que se pode lucrar através dos recursos plantados ou coletados, mas o quanto se pode deixar de gastar ao utilizá-los. Estudo realizado por Pasa (2007) em Comunidades do Bambá em Cuiabá, Mato Grosso, demonstrou que os quintais possibilitam a produção de alimentos para a subsistência das famílias e com isso exercem um papel econômico na vida das pessoas. Além do mais, os quintais geralmente estão localizados atrás das casas, atendendo perfeitamente a demanda familiar para o plantio de espécie para consumo.

Os informantes das comunidades relataram que as plantas promovem segurança alimentar, especialmente, as frutas e legumes que possuem preços elevados para se comprar e tendo elas em seus quintais eles conseguem ter uma fonte de alimento saudável, não tendo a necessidade de comprar nos mercados e feiras. Os informantes deste trabalho explicitaram a importância do cultivo e coleta das plantas com relação a economia que fazem por não ter que comprá-las: "Aqui nós planta de tudo um pouco, porque assim nós não precisa comprar" (N.F.S. 55 anos). "A melhor coisa é você ter um chá em casa, porque você não precisa comprar remédio e ainda salvei a vida da minha neta que tava morrendo de bronquite e nada curava" (A.P. 69 anos). "Esses dias fui no mercado e me assustei com o preço das frutas, ainda bem que tenho quase tudo no quintal" (I.T. 65 anos). "O bom de ter várias coisas plantadas aqui é porque quando alguém tem uma dor de barriga, uma gripe, dor de estômago a gente não precisa ir até na cidade buscar remédio" (E.R. 39 anos).

A renda pode explicar sobre o nível de conhecimento sobre recursos vegetais e seu uso, isso porque, as 
famílias mais pobres dependem mais das plantas para seu sustento. Quanto menor a renda de uma família, mais ela irá se interessar em plantar ou coletar plantas para suprir suas necessidades alimentícias e medicinais.

Mas mesmo sem ganhar dinheiro algum, o uso dos produtos florestais em casa gera uma boa "renda invisível", enriquecendo nossa saúde e nutrição. Como os caboclos dizem: "o maior ganho para toda a família é o que você come sem ter que ir comprar"' (Shanley e Medina 2005).

A análise de regressão linear simples foi usada para testar se a variável renda explica a quantidade de plantas citadas pelos entrevistados, portanto, a variável explicativa $(\mathrm{X})$ foi considerada a renda e a variável explicada $(\mathrm{Y})$ o número de citações. $\mathrm{O}$ resulado obtido foi $\mathrm{R} 2=0,9662$ e y $=11,484 \mathrm{x}+48,287$. Com esse resultado pode ser visto que a variável renda explica a variável número de citações, pois o R-quadrado ajustado foi de 95\%, considerando uma correlação positiva significativa no modelo. Já o valor de p foi menor que 0,05 e os intervalos de confiança são positivos.

Segundo Albuquerque (2014), a renda é uma das variáveis socioeconômicas com maior poder explicativo sobre o conhecimento e/ou uso dos recursos naturais. Em geral as famílias com menor renda são mais dependentes dos recursos para sua subsistência, pois há maior necessidade de utilização desses recursos. Uma família com maior poder aquisitivo não se vê tão obrigada a conhecer os recursos vegetais, pois pode adquirilos de outra forma, então esse conhecimento não será transmitido, pois pode ser irrelevante no momento essa informação.

Com isso pode ser percebido que as plantas cultivadas ou coletadas não são tão utilizadas como fonte de renda para os entrevistados, mas são de grande importância para a segurança alimentar, pois através delas conseguem manter uma nutrição suficiente para sua família.

São vários fatores que determinam as formas de uso dos recursos vegetais e as escolhas das plantas a serem utilizadas, além de gênero, renda, idade, escolaridade, o local de origem da pessoa exerce grande influência, por isso, muitos migrantes quando saem de suas cidades/estados carregam consigo a bagagem de conhecimento herdada daquele local.

Com relação a origem dos entrevistados, aqueles oriundos da região Sul do país foram os responsáveis por citar a maior parte das plantas. Mas como o número de entrevistados dessa região foi maior do que as demais foi realizado o cálculo de citação relativa, com isso percebe-se que os moradores oriundos da região Sul do país utilizam maiores quantidades de plantas do que as oriundas das demais regiões do país, pois tiveram o maior número de citação relativa de plantas (Tabela 3).

Tabela 3 - Frequência absoluta e relativa das citações sobre os recursos vegetais utilizados nas comunidades rurais estudadas em Sinop, separadas por região de origem do entrevistado.

\begin{tabular}{lcc}
\hline Região & Frequência absoluta & Frequência relativa \\
\hline Sul & 1719 & $60 \%$ \\
Sudeste & 368 & $13 \%$ \\
Norte & 18 & $1 \%$ \\
Nordeste & 175 & $6 \%$ \\
Centro Oeste & 605 & $21 \%$ \\
\hline Total & $\mathbf{2 . 8 8 5}$ & $\mathbf{1 0 0 \%}$ \\
\hline
\end{tabular}

Com isso, mesmo a região Sul do país sendo a com maior número de informantes, quando se padroniza os dados, ela continua com o maior número de citações, seguida da região Centro Oeste, Sudeste, Nordeste e 
Norte.

Para verificar a relação do entrevistado com o uso das plantas, uma das questões levantadas foi o tempo que ele trabalha com plantas, ou seja, quando iniciou a relação do entrevistado com o cultivo ou coleta de plantas para algum uso. Através desse questionamento foi obtido que $85 \%$ dos entrevistados sempre utilizaram recursos vegetais em seu cotidiano. Outros $8 \%$ informaram que passaram a utilizar as plantas quando se mudaram para as comunidades de residência, por possibilitar um espaço adequado para cultivo, o que não possuíam antes.

O tempo de residência na comunidade pode explicar a quantidade de espécies conhecidas pelos entrevistados, bem como suas formas de utilização. Geralmente quando as pessoas residem há mais tempo em determinado local elas vivenciam maiores interações com outros moradores daquele local, absorvendo, assim, um pouco do conhecimento de cada um com quem ele se relacionou. Além disso, o contato com os recursos locais também é maior, por estar em determinado local há mais tempo, é possível ter passado por regiões mais afastadas do meio em que vive, conhecendo diferentes recursos vegetais que não são tão acessíveis.

Segundo Lima (1996), o conhecimento etnobotânico permanece bem conservado e tende a aumentar conforme o tempo de permanência das pessoas em tal comunidade aumenta, isso porque o tempo de residência no local e relativo isolamento possibilita o maior conhecimento de recursos vegetais.

Os pais foram os principais responsáveis por repassar o conhecimento sobre as formas de utilização de plantas aos entrevistados, com $71 \%$ das respostas. Outros $15 \%$ informaram que a família de uma forma geral influenciou na utilização de recursos vegetais. O conhecimento sobre as plantas foi obtido de diversas formas, com vizinhos, amigos, cursos, pessoas mais velhas, entre outros. Porém, quando questionado aos entrevistados se estão repassando esses conhecimentos as respostas obtidas mostram que $57 \%$ tem transmitido e 43\% não. A existência dos recursos vegetais domesticados ou cultivados resulta de um processo cumulativo de conhecimentos, de uma transmissão temporal através de gerações (Emperaire 2006).

Uma possível explicação para pessoas que não estão repassando o conhecimento é porque os filhos não se interessam em aprender ou porque trabalham fora e não possuem tempo para se preocupar com plantas e preferem comprar. Já aqueles que estão repassando as informações disseram que os principais receptores são os filhos, com 70\% das respostas, mas que passam também para amigos, vizinhos, família ou para quem precisar e buscar esse tipo de informação.

Essa falta de interesse dos jovens em aprender sobre os recursos vegetais com pessoas mais velhas pode causar uma erosão no conhecimento, pois comprometerá a transmissão de uma geração para outra e o aprendizado será interrompido (Albuquerque 2006). Uma solução para essa situação seria armazenar o conhecimento, seja em documentos ou outras mídias, para que assim, esse seja assegurado (Ghosh e Sahoo 2011).

Uma das questões que influenciam na transmissão de conhecimento entre gerações é o processo de urbanização. A cidade de Sinop cresce a cada ano e com isso os limites entre o centro urbano e as comunidades estão ficando cada vez mais próximos, então o acesso a produtos comprados é facilitado, não havendo a necessidade dos moradores de comunidades se preocuparem em plantar, pois podem ir facilmente aos mercados ou feiras adquirir os produtos que precisam. Já na comunidade Agrovila na Gleba Mercedes 05, que fica mais de $100 \mathrm{~km}$ distante do perímetro urbano de Sinop há maior necessidade de se ter nos quintais os recursos vegetais mais utilizados, pois inviabiliza ir até a cidade buscar os produtos.

Além disso, os jovens tem se desinteressado na utilização de recursos vegetais, muitas vezes, devido a essa proximidade dos centros urbanos, que causa maior interesse nos jovens em praticar atividades ligadas as cidades. 
Para Albuquerque (2014), a urbanização é um processo em constante e acelerado crescimento, de forma que os limites entre centros urbanos e comunidades anteriormente isoladas tornam-se cada vez mais sutis. Como resultado, essa proximidade tem levado a uma hibridização dos conhecimentos e das práticas de comunidades locais com aqueles relacionados a modernidade e as novas tecnologias.

Esses conhecimentos que são repassados entre gerações geralmente ocorrem quando os filhos observam as formas de coleta e preparo de plantas que seus pais utilizam, mas com esse distanciamento entre os jovens e a cultura de utilização de plantas esses conhecimentos vão sendo perdidos. Também, essa "modernização" traz consigo novas opções de cuidados com a saúde e certa desvalorização da cultura local, à qual os jovens são o grupo mais sensível, reforçando a tendência de perda ou abandono das práticas tradicionais, as relações com a roça e com a mata de galeria, festas, danças e crenças (Amorozo 2002).

Outro fator que ocorre com a urbanização é o menor acesso às áreas de reservas florestais ou a necessidade de mudança do local em que vive pelo aumento populacional. Um caso específico de uma entrevistada, pode ser citado: ela residia em uma determinada comunidade, porém precisou se mudar, pois a área em que estava situada foi loteada e só estava restando a sua chácara naquele local, então para não atrapalhar os planos da construtora responsável ela trocou a chácara que residia, por outra na comunidade Brígida. A solução que ela encontrou para não perder as plantas que utilizava foi produzir mudas em pequenos vasos para transportar para a sua nova residência e, durante a entrevista, desabafou: "É triste deixar tudo o que eu plantei com tanto carinho para trás, ainda mais sabendo que vai ser tudo destruído" (N.F.S. 55 anos).

Outra consequência do avanço da urbanização é a destruição de parte da vegetação em algumas regiões, ocasionando a perda do conhecimento tradicional sobre as propriedades terapêuticas de algumas plantas medicinais (Martins 2013).

\section{A cultura de utilização das plantas}

Os conhecimentos sobre plantas dependem da região do país a qual a pessoa pertence, pois cada região detém uma riqueza diferente de espécies de plantas e isso depende de sua cultura, tradição, estilo de vida. Dentro das características culturais, os processos de imigração de populações humanas também resultam em alterações no conhecimento sobre os recursos vegetais (Pieroni e Vandebroek 2007).

O fato de a maioria da população entrevistada ser oriunda da região Sul do país em todas as comunidades não é isolado, ele ocorre porque o município foi colonizado por moradores dessa região do Brasil, portanto também possui grande parte de sua população oriunda dessa região.

A maior parte dessas famílias moram nas respectivas comunidades há mais de dez anos. O nível de escolaridade predominante é o ensino fundamental incompleto e a renda fica em torno de um até dois salários mínimo (Tabela 4).

A predominância na maioria das comunidades são das famílias botânicas Anacardiaceae, Lamiaceae, Myrtaceae e Rutaceae. As principais plantas de cada família foram a mangueira (Mangifera indica L.), a cidreira (Melissa officinalis L.), a goiabeira (Psidium guajava L.) e o limoeiro (Citrus limon (L.) Burman F.) respectivamente. As plantas que pertencem a essas famílias são a base para a preparação de medicamentos que as famílias utilizam e também aquelas que servem como alimentos. 
Tabela 4 - Resumo dos principais índices para as comunidades rurais estudadas em Sinop, considerando aquele que foi predominante na respectiva comunidade.

\begin{tabular}{|c|c|c|c|c|c|c|}
\hline Comunidade & Região & $\begin{array}{l}\text { Faixa } \\
\text { etária }\end{array}$ & Ocupação & $\begin{array}{l}\text { Total de } \\
\text { citações }\end{array}$ & $\begin{array}{c}\text { Família mais } \\
\text { citada }\end{array}$ & $\begin{array}{c}\text { Planta mais } \\
\text { citada }\end{array}$ \\
\hline Brígida & Sul & $61-70$ & Do lar & 288 & Lamiaceae & Hortelã \\
\hline 11 de Julho & Sul & $51-60$ & Aposentado & 558 & Lamiaceae & Manga \\
\hline Adalgisa & Sul & $51-60$ & Do lar & 351 & Rutaceae & Limão \\
\hline $\begin{array}{l}\text { Gleba Merce- } \\
\text { des } 05\end{array}$ & $\begin{array}{l}\text { Centro } \\
\text { Oeste }\end{array}$ & $41-50$ & $\begin{array}{l}\text { Produtor } \\
\text { rural }\end{array}$ & 471 & Lamiaceae & Goiaba \\
\hline Planalto & Sul & $31-40$ & Do lar & 566 & Rutaceae & Manga \\
\hline Bom Jardim & Sul & $41-50$ & Do lar & 352 & Lamiaceae & Manga \\
\hline Monalisa & $\begin{array}{l}\text { Centro } \\
\text { Oeste }\end{array}$ & $21-40$ & Do lar & 299 & Myrtaceae & Manga \\
\hline
\end{tabular}

A mangueira foi citada diversas vezes pelos entrevistados, isso por conta de sua versatilidade, ela serve para sombrear o quintal, por isso muitos moradores a plantam no entorno na residência, o seu fruto serve como alimento, para preparo de sucos, doces, entre outros, além disso, ela também foi citada como medicinal, onde suas folhas e raízes podem ser utilizadas para tratar algumas enfermidades. O limoeiro também tem diversas finalidades, como suco, doces, preparo de chás. A goiabeira proporciona sombra e o consumo do fruto. E o hortelã foi citado principalmente no preparo de chás para gripe e como calmante, além de servir como complemento em sucos. A Tabela 5 ilustra as principais famílias botânicas citadas por cada comunidade estudada.

Tabela 5 - Famílias botânicas mais citadas nas comunidades rurais estudadas em Sinop.

\begin{tabular}{lccccccc}
\hline Família & Brígida & Julho & Adalgisa & Agrovila & Planalto & $\begin{array}{c}\text { Bom Jar- } \\
\text { dim }\end{array}$ & Monalisa \\
\hline Anacardiaceae & 12 & 54 & 36 & 45 & 51 & 44 & 40 \\
Annonaceae & 0 & 0 & 0 & 16 & 0 & 0 & 0 \\
Arecaceae & 0 & 16 & 23 & 0 & 34 & 12 & 20 \\
Brassicaceae & 12 & 0 & 0 & 0 & 0 & 0 & 0 \\
Caricaceae & 0 & 0 & 0 & 0 & 23 & 0 & 9 \\
Compositae & 20 & 0 & 0 & 0 & 0 & 0 & 0 \\
Euphorbiaceae & 0 & 0 & 0 & 21 & 0 & 25 & 0 \\
Fabaceae & 12 & 0 & 0 & 0 & 0 & 0 & 0 \\
Lamiaceae & 59 & 68 & 14 & 83 & 58 & 73 & 41 \\
Malpighiaceae & 0 & 16 & 0 & 0 & 0 & 12 & 0 \\
Moraceae & 0 & 29 & 16 & 0 & 0 & 0 & 0 \\
Musaceae & 0 & 0 & 0 & 0 & 25 & 0 & 15 \\
Myrtaceae & 14 & 57 & 37 & 53 & 54 & 43 & 45 \\
Poaceae & 0 & 0 & 16 & 24 & 0 & 0 & 0 \\
Rutaceae & 20 & 63 & 42 & 75 & 64 & 35 & 32 \\
\hline
\end{tabular}

Nas comunidades Brígida, 11 de Julho, Gleba Mercedes e Bom Jardim a predominância foi das espécies pertencentes a família Lamiaceae. Nas comunidades Adalgisa, Planalto as plantas da família Rutaceae foram 
as mais significativas e na comunidade Monalisa os entrevistados responderam um maior número de vezes as plantas da família Myrtaceae.

A região de origem de cada pessoa diz muito sobre as plantas que elas costumam utilizar, e o Brasil sendo um país com ampla diversidade proporciona diferentes tipos de recursos vegetais para cada região. E com isso, os costumes e culturas são adaptados para a realidade do local em que residem após a migração, criando uma nova identidade para esse local (Figura 2).

Os entrevistados, em sua maioria, viviam na região Sul do país antes de chegarem as respectivas comunidades, portanto, quando se observa a quantidade de espécies de plantas citadas conforme a região de origem há uma predominância dessa região. Seguida dela há as citações da região Centro Oeste, em sua maioria são pessoas que nasceram no Estado de Mato Grosso ou que vieram muito pequenas para o Estado acompanhando seus pais.

Figura 2 - Citação de plantas por região de origem dos entrevistados das comunidades rurais de Sinop.

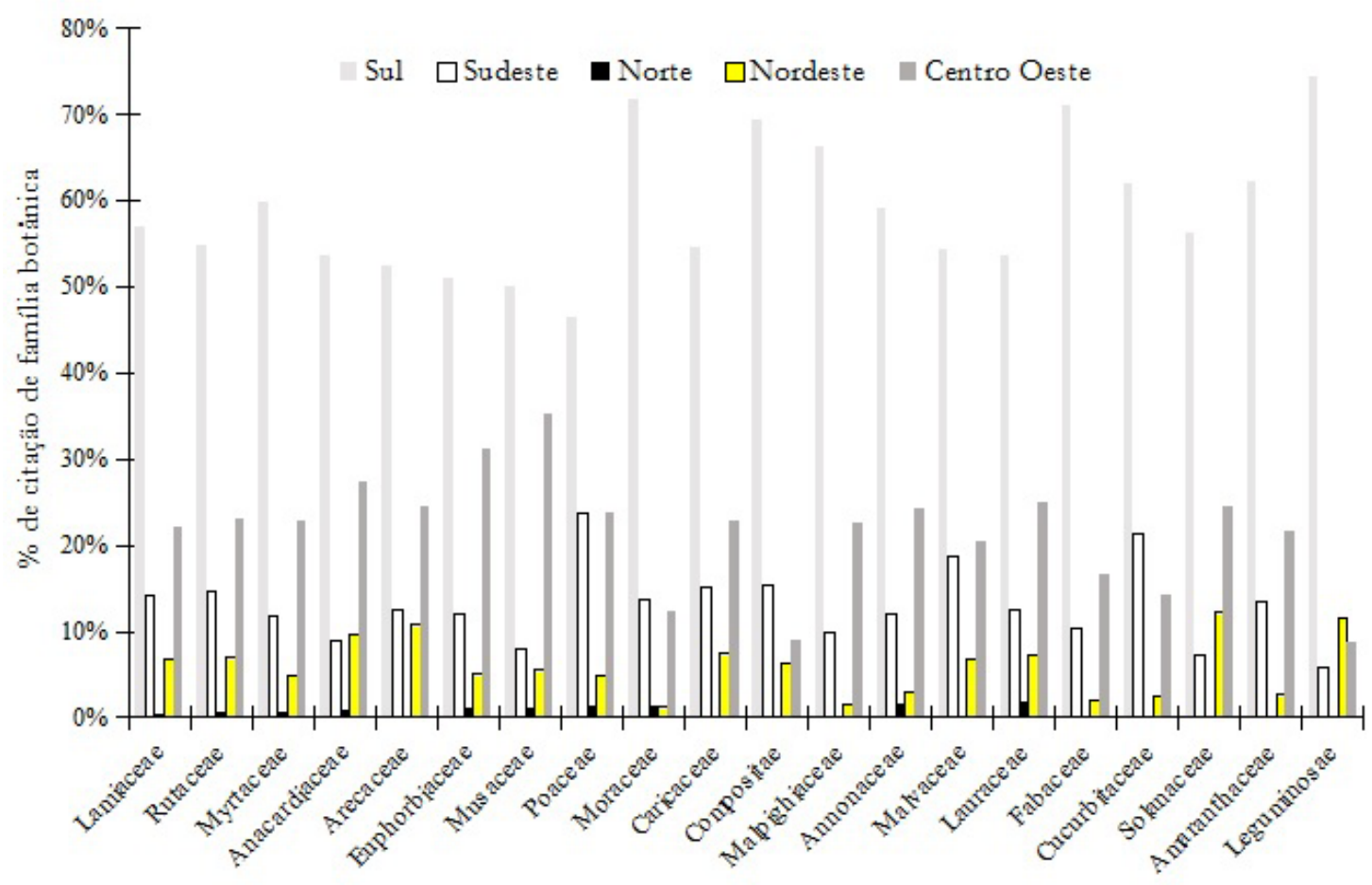

Nesse sentido, o estudo de quintais, na percepção de habitantes de diferentes regiões, especialmente tropicais, assume uma importância no mundo atual, especialmente por se tratar de espaços de conservação e demonstração de saberes acumulados ao longo do tempo, perpassando gerações (Novais et al. 2011).

De uma maneira geral, pode-se perceber que as respostas sobre as famílias botânicas são muito parecidas, isso ocorre porque, quando há uma migração por parte da população, elas mudam o cenário que estão acostumadas a viver. No início as pessoas tendem a manter a cultura na qual estão acostumadas, mas com o passar do tempo acabam incorporando em seu cotidiano características que adquirem com a vivência com pessoas de outros locais. Estes indivíduos trouxeram consigo valores, crenças e experiências vividas que, associadas àquelas das comunidades anteriormente estabelecidas na região, compõem o acervo cultural desta nova sociedade formada (Viu et al. 2010). Além disso, muitas plantas que eram utilizadas antes, podem não estar disponíveis nesse novo ambiente, por isso há a necessidade de se adaptar a usar as plantas que são mais facilmente adquiridas.

O ser humano tem uma relação de afeto com o seu local de origem, e isso pode explicar o motivo dele 
querer cultivar plantas que remetam a cidade/Estado de onde vieram. Segundo Amorozo (2002a), os migrantes tem uma relação estreita com as suas regiões de origem, reproduzindo em quintais mato-grossenses réplicas de quintais do Sul e Sudeste do Brasil, inclusive com espécies típicas. As plantas e demais elementos presentes no quintal promovem a ligação do cotidiano desta família com o seu local de origem e contribuem na manutenção de características culturais por intermédio do manejo adotado. Essas manifestações revelam o sentimento afetivo e a percepção desses seres humanos em relação aos seus locais de origem.

Ainda segundo Amorozo (2002a), “a fisionomia de quintais e jardins é moldada por combinações e variações de sua estrutura, função e tamanho. Seu conteúdo e seu destino estão firmemente atrelados à sua história, que é a história da família ou famílias que ocuparam o domić́lio e refletem situações e experiências vividas por seus membros. Assim, quintais e jardins de migrantes podem conter plantas das regiões de origem, quintais antigos podem estar conservando variedades raras, ou mesmo algumas que havia no ambiente original antes de sua conversão para agricultura extensiva”.

Além disso, a produção nos quintais, especialmente a hortifrutífera, permite à população manter uma baixa dependência de produtos adquiridos externamente, ocasiona impactos mínimos sobre o ambiente, conserva os recursos vegetais e a riqueza cultural, fundamentada no saber e na cultura dos moradores locais (Pasa 2004).

\section{Forma como as plantas promovem qualidade de vida aos entrevistados}

Os entrevistados foram questionados sobre a qualidade de vida que as plantas poderiam lhe proporcionar, ou seja, se eles acreditam que as plantas possibilitam uma vida melhor. Para a maioria (71\%) a utilização de plantas no seu cotidiano pode trazer benefícios para a saúde (Figura 3), porque são mais saudáveis e geralmente cultivadas por eles mesmos, que lhes garante que não há agrotóxico. "É tudo cuidado por nós, não tem veneno e faz. bem pra saúde, porque comemos tudo que é tipo de fruta" (W.E. 60 anos), "Porque comemos de tudo um ponco e sou en que cuido e sei de onde vem" (A.R. 78 anos).

A utilização dos recursos vegetais como medicamento também foi bem expressivo, muitos entrevistados informaram que evitam ir até a farmácia, pois possuem o básico para o preparo de chás em casa. Uma entrevistada relatou: "Agora estou lendo a Bíblia, mas en gosto muito de ler livros e estudar sobre as plantas, en acho que elas podem substituir os remédios de farmácia" (D.A. 73 anos). Outro entrevistado disse: "o remédio da farmácia é bom de um lado, mas atrapalha de outro, então prefiro os chás" (O.R. 65 anos). Uma senhora destacou a importância da transmissão do conhecimento sobre a utilização de plantas para fins medicinais: "Meu marido não compra remédio, ele usa a Buta pra quase tudo e os meus filhos gostam do que ensino pra eles porque dai eles não precisam comprar remédio” (C.C. 65 anos). Uma entrevistada relatou que evitou uma operação de rins somente tomando chás: "Em outra comunidade tem uma senhora chamada Dona D., eu pagava $\mathrm{R} \$ 47,00$ de consulta pra ela e ia a cada 21 dias pra pegar as folhas dos chás, eu não sei que plantas que eram, mas me curei dos rins assim e não precisei faz̧er uma operação que os médicos tinham dado como certa, mas tem que faz̧er o tratamento dela certinho" (S.I.O. 63 anos).

A utilização das plantas também serve como alimentação para essas famílias e um dos entrevistados relatou: "não gosto de ter que ir ao mercado para comprar as coisas, prefiro utilizar tudo aquilo que aprendi no sítio" (E.E. 62 anos). A citação das plantas como incremento da renda aconteceu por parte de alguns moradores que vendem mandioca, verdura e também por aqueles que pretendem vender alguma planta no futuro, como é o caso de um informante que diz estar plantando limão para a venda. Além disso, evitam de ter que comprar gerando economia. 
Figura 3 - Motivo elencado pelos entrevistados nas comunidades rurais de Sinop para acreditarem que as plantas podem trazer qualidade de vida.

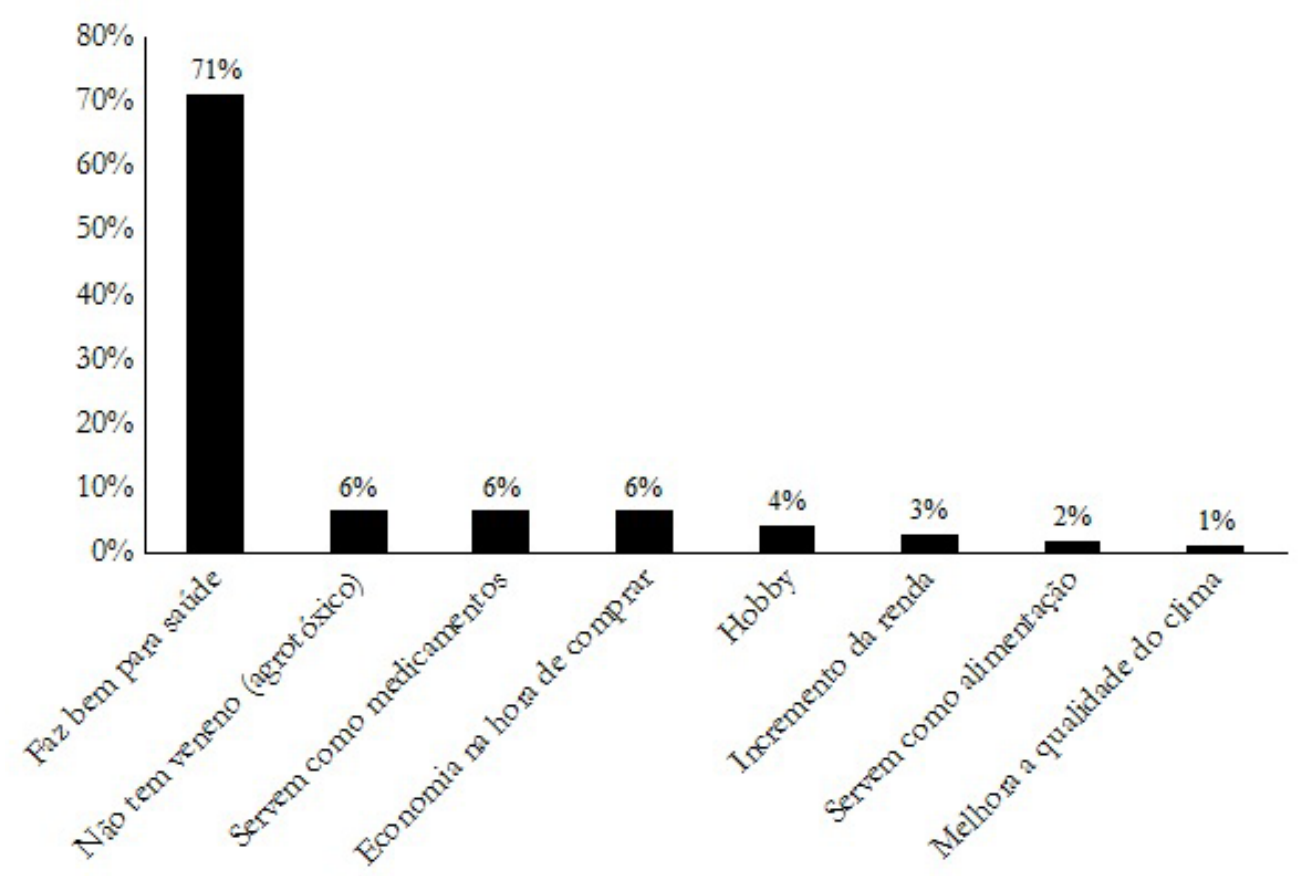

O cultivo das plantas como hobby também pode ser destacado, pois muitos entrevistados disseram que essa prática ajuda a passar o tempo e traz uma grande satisfação para eles. "Eu gostava de fazer artesanato, pegava cipó do mato pra fažer, só parei porque fiquei doente" (M.L.S. 59 anos), Eu gostava muito de cuidar das plantas, era um prazer, mas fiquei doente e não posso mais ficar andando muito, me sinto inútil agora" (G.M. 81 anos). Um entrevistado comparou o cultivo das plantas com o cuidado de bebês: "As plantas são como bebês que precisam de cuidado" (A.A. 46 anos). As plantas como bobby é importante, especialmente, para as pessoas mais velhas, pois como passam muito tempo sozinhas elas usam as plantas como forma de entretenimento, se apegam ao cultivo para suprir a falta de companhia de outras pessoas.

Duas entrevistadas disseram que gostam muito de plantar, mas que no momento a proximidade de sua propriedade com lavouras prejudica as plantas de seu quintal, pois segundo elas: "o veneno ao redor estraga todas as coisas que planto" (E.C.S. 59 anos), "não planto muito porque o veneno mata tudo" (R.M.S. 34 anos). Além dessas, uma entrevistada disse não plantar muita coisa por falta de tempo, mas que geralmente utiliza as plantas da casa do seu pai que reside ao lado.

Dois entrevistados responderam que acreditam sim, que as plantas possam ter benefícios, mas um deles disse não ter o costume de usar, pois prefere utilizar as coisas prontas compradas em mercados e o outro disse não usar porque não tem muito conhecimento e tem medo de usar alguma planta que seja tóxica.

Como pode ser visto, os recursos vegetais trazem qualidade de vida para essas pessoas, não somente pelos benefícios à saúde, porque servem como alimentação e remédio ou por serem mais saudáveis pelo fato de serem orgânicos e não possuírem agrotóxico, mas também por melhorarem o clima, tornando o local mais fresco, por servirem como passatempo, auxiliarem no incremento da renda e na economia com as compras nos mercados.

Desta maneira, é importante valorizar o conhecimento das populações locais para a conservação da biodiversidade, pois com o conhecimento tradicional é possível conhecer o uso das espécies nativas. Além disso, 
é possível identificar determinadas pressões que podem estar ocorrendo neste ambiente, e este, é um aspecto relevante para o planejamento de ações que busquem um equilibro entre as necessidades das populações e a disponibilidade do recurso na natureza (Albuquerque e Andrade, 2002).

\section{Plantas disponiveis nos quintais mas não utilizadas}

Foi perguntado aos moradores das comunidades rurais de Sinop sobre as plantas que eles tinham em seus quintais mas que não faziam uso, bem como o motivo dessa não utilização. Houve 63 citações de plantas e a principal planta citada como não utilizada, mas que estava disponível nos quintais foi o noni (Morinda citrifolia L.), foi dito que ele pode servir para auxiliar no tratamento do câncer, problemas do coração, para o emagrecimento e também que ela poderia ser secado e colocado na ração dos animais, como o cavalo, por exemplo. E as motivações para o não uso foram: plantou na época da divulgação do noni, mas que depois viu que não tinha todos aqueles benefícios; não sabe como usar; por achar que não ajuda em nada e ainda pode prejudicar o estômago e por achar fedido. Essas são explicações dos moradores das comunidades estudadas referente ao não uso do noni. Um dos motivos de várias pessoas terem o noni em seus quintais foi a influência da mídia, que divulgou que ele servia para diversos fins durante um período.

Foram citadas também algumas árvores como a Embaúba (Cecropia pachystachya Travel), Figueira (Ficus carica L.), Ipê (Tabebuia aurea (Mart.) Bur.), Teca (Tectona grandis L.f.) e Aroeira (Schinus areira L). O motivo principal da não utilização dessas árvores é por não saberem para que serve ou por elas terem nascido por conta nas propriedades. Apenas a Teca foi citada como potencial para a fabricação de móveis.

Com isso pode ser percebido que mesmo com a difusão de conhecimento entre as gerações e as diferentes culturas nas comunidades estudadas, existem inúmeras plantas que não são utilizadas pelo desconhecimento de suas propriedades ou por não saberem como usar. Existem ainda diversas plantas com finalidades definidas pelos entrevistados, mas que só não foram utilizadas ainda por existirem substitutos para elas ou por ainda não ter sido necessário esse uso, como por exemplo, a romã que serve para a dor de garganta, mas que não é usado porque prefere usar a tansagem. Segundo Roque (2009) surge a necessidade de se desenvolver trabalhos que levantem as potencialidades dos recursos vegetais, caracterizando-os e sugerindo maneiras que ampliem a produtividade deste recurso de uma forma sustentável. A etnobotânica auxilia na identificação desses usos, apontando as maneiras com as quais determinadas populações fazem o manejo da vegetação.

\section{Conclusão}

As pessoas que vieram da região Sul do país são a maioria dos entrevistados e também são os que citaram um maior número de recursos vegetais, com isso a utilização de plantas mantem vivo os laços com a cultura de sua região.

A renda dos entrevistados é baixa e como ela é uma das variáveis que consegue explicar a quantidade de plantas que os entrevistados conhecem ou utilizam, percebe-se que as pessoas com menores rendas são as mais propensas a utilizarem os recursos fornecidos pelo meio ambiente.

As pessoas idosas são aquelas que detém a maior parte do conhecimento e as que mais utilizam as plantas. 
Já os jovens preferem interagir com atividades relacionadas a centros urbanos do que participar do cultivo ou da coleta de plantas realizadas por seus familiares.

A transmissão de conhecimentos é importante para manter a cultura de uso dos recursos vegetais viva, mas observou-se que o conhecimento tradicional sobre o cultivo e uso de plantas está sendo perdido nas comunidades estudadas.

É possível verificar a forte relação entre os entrevistados e o uso das plantas, já que os entrevistados afirmaram que as plantas trazem alguma forma de qualidade de vida e podem usufruir de seus diversos benefícios. Além disso, demonstraram amor em cultivar e passar um tempo cuidando de suas plantas, fazem isso porque essa interação traz tranquilidade e satisfação.

Os fatores socioculturais como a região de origem, a renda e o tempo de moradia encontrados nas comunidades podem influenciar as plantas a serem utilizadas e a sua forma de utilização. Como esses fatores são similares entre as comunidades entrevistadas, as famílias botânicas mais utilizadas são semelhantes, bem como as plantas que são a base da preparação de medicamentos e alimentos essenciais para os entrevistados. Desta forma o conhecimento sobre o uso dos recursos vegetais pode ajudar no bem-estar dos indivíduos de diversas formas.

\section{REFERÊNCIAS}

Albuquerque UP, Andrade LHC. 2002. Uso de recursos vegetais da Caatinga: O caso do Agreste do Estado de Pernambuco (Nordeste do Brasil). Interciência, 27(7): 336-345.

Albuquerque UP. 2006. Re-examining hypotheses concerning the use and knowledge of medicinal plants: a study in the Caatinga vegetation of NE Brazil. Journal of Ethnobiology and Ethnomedicine, 2(30): 1-10.

Albuquerque UP, Alves AGC, Araújo TAS. 2007. Povos e Paisagens: Etnobiologia, Etnoecologia e Biodiversidade no Brasil. Recife: NUPEEA/UFRPE, 148 p.

Albuquerque UP, Lucena RFP de, Neto EMFL. 2010. Seleção dos participantes da pesquisa. In: Albuquerque UP, Lucena RF, Paiva de, Cunha LVFC da. Métodos e técnicas na pesquisa etnobiológica e etnoecológica. Recife: NUPEEA, p 21-37.

Albuquerque UP. 2014. Introdução à Etnobiologia. Recife: NUPEEA, 189 p.

Amorozo MCM. 2002. Uso e diversidade de plantas medicinais em Santo Antonio do Leverger, MT, Brasil. Acta Botânica Brasílica, 16(2): 189-203.

Amorozo MCM. 2002a. Traditional agriculture, enduring spaces and the joy of planting. In: Albuquerque UP, Alves AGC, Silva ACBL, Silva VA. (Orgs.). Actualities in Ethnobiology and Ethnoecology. Recife: SBEE, p. 123-131.

Amorozo MCM. 2002b. Agricultura tradicional, espaços de resistência e o prazer de plantar. In: Albuquerque UP, Alves AGC, Silva ACBL, Silva VA (Org.). Atualidades em etnobiologia e etnoecologia. Recife: Sociedade Brasileira de Etnobiologia e Etnoecologia, p.123-131. 
Bernard HR. 2006. Research methods in cultural anthropology: Qualitative and quantitative approach, 4th ed., United States of America: Altamira Press, 803 p.

Amorozo MCM. 2008. Os quintais-funções, importância e futuro. In: Guarim Neto G, Carniello MA. (Orgs.). Quintais matogrossenses: espaços de conservação e reprodução de saberes. Cáceres: EDUNEMAT, p. $15-26$.

Balick MJ, Cox PA. 1997. Plants, people and cultures: The science of ethonobotany. New York: Scientific American Library, 228 p.

Dias CAA. 2007 Procedimentos de medição e aquisição de dados de uma torre micrometeorológica em Sinop-MT. Dissertação de Mestrado. Cuiabá: Universidade Federal de Mato Grosso, 75 p.

Diegues AC. 2000. Etnoconservação da natureza: enfoques alternativos. In:Diegues AC.(Org.).Etnoconservação: novos rumos para a proteção da natureza nos trópicos. São Paulo: Hucitec, p. 1-46.

Emperaire L. 2006. Histórias de plantas, histórias de vida: uma abordagem integrada da diversidade agrícola tradicional na Amazônia. In: Kubo RR et al. (Orgs.). Atualidades em etnobiologia e etnoecologia, $1^{\text {a }}$ ed. Recife: NUPEEA/Sociedade Brasileira de Etnobiologia e etnoecologia, p. 187-198.

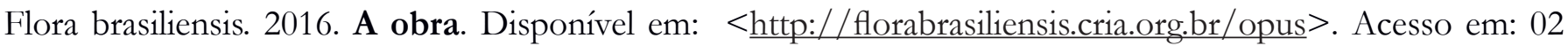
ago. 2016.

Flora do Brasil. 2016. Lista de espécies da flora do Brasil. Disponível em: < http://floradobrasil.jbrj.gov. br>Acesso em: 08 ago. 2016.

Fracaro FA, Guarim VLMS. 2008. Uso da biodiversidade em quintais do município de Juína. In: Guarim-Neto G, Carniello MA. Quintais mato-grossenses - espaços de conservação e reprodução de saberes. Cáceres: Editora Unemat, p. 63-78.

Ghosh PK, Sahoo B. 2011. Indigenous Traditional Knowledge. Orissa Review, 67(6): 66-71.

Hanazaki N. 2004. Capítulo 1: Etnobotânica. In: Begossi A, Leme A, Seixas CS, Castro F de, Pezutti J, Hanazaki N, Peroni N, Silvano RAM. Ecologia de Pescadores da Mata Atlântica e da Amazônia. São Paulo: Hucitec. p.37- 57.

Hanazaki N. 2006. Conhecimento caiçara para o manejo de recursos naturais. In: Albuquerque UP et al. Atualidade em etnobiologia e etnoecologia. 2. ed. Recife: NUPEEA, p. 17-23.

Lima RX de. 1996. Estudos etnobotânicos em comunidades continentais da área de Guaraqueçaba. Dissertação de Mestrado. Curitiba: Universidade Federal do Paraná, 123 p.

Lucas FCA et al. 2015. Usos e benefícios das plantas em comunidades rurais de Capanema, Pará, Brasil. Cadernos de Agroecologia, 10(3): 1-5.

Lunelli NP. 2014. Conhecimento e uso de espécies arbóreas por agricultores do Vale do Ribeira. 
Dissertação de Mestrado. São Paulo: Instituto de Botânica da Secretaria de Estado do Meio Ambiente, 109 p.

Martin GJ. 1995. Ethnobotany: a methods manual. London: Chapman \& Hall, 268p.

Martins WMO. 2013. Etnoconhecimento de plantas de uso medicinal na microrregião do Vale do Juruá, Acre, Brasil. Enciclopédia Biosfera, 9(16): 2540-2547.

Novais AN, Guarim Neto G, Guarim VLMS, Pasa MC. 2011. Os quintais e a flora local: um estudo na Comunidade Jardim Paraiso, Cáceres-MT, brasil. Revista Biodiversidade, 10(1): 3-12

Oliveira WA. 2013. Os Recursos Vegetais E O Saber Local Nos Quintais Da Comunidade De Santo Antônio Do Caramujo, Cáceres, Mato Grosso, Brasil. Dissertação de Mestrado. Cuiabá: Universidade Federal de Mato Grosso, 104 p.

Pasa MC. 2004. Etnobiologia de uma comunidade ribeirinha no alto da bacia do rio Aricá-Açú, Cuiabá, Mato Grosso, Brasil. Tese de Doutorado. São Carlos: Universidade Federal de São Carlos, 174 p.

Pasa MC. 2007. Um olhar etnobotânico sobre as comunidade do Bambá, Cuiabá, Mato Grosso. Cuiabá: Entrelinha EdUFMT. 144 p.

Pasa MC. 2011. Saber local e medicina popular: a etnobotânica em Cuiabá, Mato Grosso, Brasil. Boletim do Museu Paraense Emílio Goeldi, 6(1): 179-196.

Pieroni A, Vandebroek I. 2007. Traveling cultures and plants: The ethnobiology and ethnopharmacy of human migrations. 1st. ed., New York - Oxford: Berghahn Books, 276 p.

Pilla MAC, Amorozo MCM. 2009. O conhecimento sobre os recursos vegetais alimentares em bairros rurais no Vale do Paraíba, SP, Brasil. Acta botânica brasílica 23(4): 1190-1201.

Poderoso RA. 2012. Conhecimento local sobre plantas no entorno da floreta nacional de Ibirama-SC. Dissertação de Mestrado. Florianópolis: Universidade Federal de Santa Catarina, 150 p.

Roque AA. 2009. Potencial de uso dos recursos vegetais em uma comunidade rural do semiárido do Rio Grande do Norte. Dissertação de Mestrado. Natal: Universidade Federal do Rio Grande do Norte, 79 p.

Ruddle K. 2000. Systems of Knowledge: Dialogue, Relationships and Process. Environment, Development and Sustainability, 2:277-304.

Schutkowski H. 2006. Human ecology: biocultural adaptations in human communities. Berlin: Springer, $306 \mathrm{p}$.

Shanley P, Medina G. 2005. Frutíferas e Plantas Úteis na Vida Amazônica. Belém: CIFOR \& Imazon, 300 p. Souza AP, Mota LL, Zamadei T, Martim CC, Almeida FT, Paulino J. 2013. Classificação climática e balanço hídrico climatológico no Estado de Mato Grosso. Nativa: Pesquisas Agrárias e Ambientais, 1(1): 34-43.

Strachulski J, Floriani N. 2013. Conhecimento popular sobre plantas: um estudo etnobotânico na comunidade 
rural de Linha Criciumal, em Cândido de Abreu- PR. Revista Geografar, 8(1): 125-153.

The Plant List. 2016. A working list of all plant species. Disponível em: < $\underline{\text { http: } / / \text { www.theplantlist.org }>\text { Acesso }}$ em: 08 ago. 2016.

Veiga JB da. 2011. Etnobotânica e etnomedicina na reserva de desenvolvimento sustentável do Tupé, baixo Rio Negro: plantas antimaláricas, conhecimentos e percepções associadas ao uso e à doença. Tese de Doutorado. Manaus: Instituto Nacional de Pesquisas da Amazônia, 154 p.

Viu AFM, Viu MAO, Campos, LZO. 2010. Etnobotânica: uma questão de gênero? Revista Brasileira de Agroecologia, 5(1): 138-147. 